\title{
Nerve impulse transmission pathway-focused genes expression analysis in patients with primary hypothyroidism and autoimmune thyroiditis
}

\author{
Iryna I. Bilous ${ }^{1}$, Mykhaylo M. KordA ${ }^{2}$, Inna Y. KrynYTSKA ${ }^{2}$, Aleksandr M. KAMYshnY I ${ }^{3}$
}

\author{
${ }^{1} H S E E U$ "Bukovinian State Medical University", Chernivtsi, Ukraine; ${ }^{2}$ I. Horbachevsky Ternopil National Medical \\ University, Ternopil, Ukraine; 'Zaporozhye State Medical University, Zaporizhzhia, Ukraine \\ E-mail: Iryna.bilous2017@gmail.com
}

Objective. Thyroid hormones have important actions in the adult brain. They regulate genes expression in myelination, differentiation of neuronal and glial cells, and neuronal viability and function.

Methods. We used the pathway-specific real-time PCR array (Neurotrophins and Receptors RT2 Profiler PCR Array, QIAGEN, Germany) to identify and verify nerve impulse transmission pathway-focused genes expression in peripheral white blood cells of patients with postoperative hypothyroidism, hypothyroidism as a result of autoimmune thyroiditis (AIT) and AIT with elevated serum an anti-thyroglobulin (anti-Tg) and anti-thyroid peroxidase (anti-TPO) antibodies.

Results. It was shown that patients with postoperative hypothyroidism and hypothyroidism resulting from AIT had significantly lower expression of BDNF and CBLN1. In patients with AIT with elevated serum anti-Tg and anti-TPO antibodies, the expression of GDNF was significantly down-regulated and the expression of PNOC was up-regulated. The expression levels of MEF2C and NTSR1 were decreased in the group of patients with postoperative hypothyroidism and AIT, correspondingly.

Conclusions. The results of this study demonstrate that AIT and hypothyroidism can affect the expression of mRNA nerve impulse transmission genes in gene specific manner and that these changes in gene expressions can be playing a role in the development of neurological complications associated with thyroid pathology. Detection of the transcriptional activity of nerve impulse transmission genes in peripheral white blood cells can be used as an important minimally invasive prognostic marker of the risk for developing neurological complications comorbid with thyroid pathology.

Key words: neurotrophin, mRNA, autoimmune thyroiditis, hypothyroidism

Synapses are specialized asymmetric cell-cell connections permitting the controlled transfer of an electrical or chemical signal between a presynaptic neuronal cell and a postsynaptic target cell (e.g. neuron or muscle) (Petzoldt and Sigrist 2014). Synaptogenesis takes place during development, learning and memory formation, and recovery after nervous system injuries (Bonner et al. 2011; Parkhurst et al. 2013; Miyamoto et al. 2016). Neurotrophins (NTFs) play an important role in synaptogenesis (Poyhonen et al. 2019). Recently analysis of synapse formation in vitro has identified various "synapse organizers" involved in this process (Fox and Umemori 2006). Synaptic plasticity depends on modifications of preexisting proteins, changes in gene expression and protein synthesis (Chen et al. 2003). Understanding the mechanisms of synapse formation in the brain, as well as molecular mechanisms that regulate the forma-

Corresponding author: Iryna I. Bilous, M.D., PhD.; Department of Nervous Diseases, Psychiatry and Medical Psychology HSEEU "Bukovinian State Medical University" (BSMU), 58002, 2, Theatralna sq., Chernivtsi, Ukraine; phone: +380954313068 ; e-mail: Iryna.bilous2017@gmail.com. 
tion and maintain of synapses will help in elucidating brain function, neural processes and mental disorders.

Since the Chernobyl accident nuclear fallout in 1986, there is a recorded increase in the incidence of thyroid diseases, mainly in Central, Northern, and Eastern Europe. In Ukraine, over the last 5 years, the number of thyroid disorders has showed a 5 -fold increase (Tronko et al. 2012; Shcherba et al. 2019). Thyroid hormones $(\mathrm{TH})$ play an important role in the adult brain. They regulate gene expression in myelination, differentiation of neuronal and glial cells, and neuronal viability and function (Bathla et al. 2016). Hypothyroidism affects mood and certain aspects of cognitive functioning (decreased information processing speed, reduced efficiency of executive functions, and poor learning). A more severe degree of hypothyroidism can mimic melancholic depression and dementia. Although the data are inconsistent, there are indications that treatment for hypothyroidism and normalization to a euthyroid state tend to improve neuropsychiatric symptoms (Kotwal et al. 2016; Juceviciute et al. 2019).

The mechanism of $\mathrm{TH}$ action in the brain is not entirely clear due to the complexity of feedback loop between neurotransmission and thyroid gland. One of the proposed pathways involves $\mathrm{TH}$ modulation of postsynaptic beta-adrenergic receptors in cerebral cortex and cerebellum. Another theory suggests TH modulation of serotonin [5-hydroxytryptamine (5-HT)] and its receptors, which results from inhibition caused by $\mathrm{TH}$ at the raphe nucleus, causing the reduction in 5-HT levels (Davis and Tremont 2007; Bathla et al. 2016).

The exact mechanism of development of neurological complications in thyroid dysfunction remains unknown and the mechanism activating thyroid hormone-regulated gene expression in adult brain is not well-understood. Transcriptome analysis is an important indicator of cell functional activity of cells (Topol et al. 2014; Putilin et al. 2016; Koval et al. 2018). Most experimental studies of regulatory genes for nerve impulse transmission, for obvious reasons, focus on the analysis of their transcriptome activity in cells of the nervous tissue. Nevertheless, the overwhelming majority of them are not only transcribed but also translated into peripheral blood cells, in particular, T- and B-lymphocytes, monocytes, neutrophils.

The aim of the study was to detect changes in the expression of regulatory genes involved in nerve impulse transmission pathway in the peripheral white blood cells of patients with different forms of thyroid disorders.

\section{Subjects and methods}

Subjects. Thirty-six patients with thyroid pathology were enrolled in the study. They were divided into 3 groups: Group 1 included 12 patients with postoperative hypothyroidism; Group 2 included 12 patients with hypothyroidism resulting from autoimmune thyroiditis (AIT); and Group 3 included 12 patients with AIT and elevated serum an anti-thyroglobulin (anti-Tg) and anti-thyroid peroxidase (antiTPO) antibodies. Control group included 12 healthy individuals, which were recruited randomly, without matching for age or sex. The informed consent was obtained from all participants and the protocol was approved by the local ethics committees of HSEEU "Bukovinian State Medical University" and Chernivtsi Regional Endocrinology Center.

Blood specimens were collected between 8 and 10 a.m. after an overnight fast. Free triiodothyronine (fT3) (normal range 3.1-6.8 pmol/L), free thyroxine (fT4) (normal range 12.0-22.0 pmol/L), thyroidstimulating hormone (TSH) (normal range 0.27 $4.2 \mathrm{mIU} / \mathrm{mL}$ ), anti-TPO (normal range $0-30 \mathrm{IU} / \mathrm{mL}$ ) and anti-Tg (normal range $0-60 \mathrm{IU} / \mathrm{mL}$ ) antibodies levels were determined by chemiluminescence assay using Cobas e411 (Roche Hitachi, Germany).

Hypothyroidism was diagnosed due to the recommendations of the American Association of Clinical Endocrinologists 2012. The diagnosis of AIT was performed according to circulating antibodies to thyroid antigens (anti-TPO and anti-Tg) and reduced echogenicity on thyroid sonogram in a patient with proper clinical features (Garber et al. 2012).

Patients under age of 18 or with any malignancy, inflammation associated rheumatic diseases or acute/ chronic infection, cases with diabetes mellitus, cases with cardiovascular or cerebrovascular diseases, pregnant women and those with chronic hepatic or renal diseases, those who use any drugs that could interfere with thyroid function were excluded from the study.

Experimental methods. We used a pathwayspecific PCR array (Neurotrophins and Receptors $\mathrm{RT}^{2}$ Profiler PCR Array, QIAGEN, Germany) to identify and verify genes expression in each individual of the studied and control groups. The Human Neurotrophin \& Receptors RT ${ }^{2}$ Profiler PCR Array is designed for expression analysis of 84 genes related to neuronal processes plus 5 housekeeping genes and 3 controls. Neurotrophic signaling molecules on this array include NFTs and neuropeptides along with their receptors. The array also contains the cytokines and receptors involved in neuronal signaling 
along with genes involved in the transmission of nerve impulses, genes involved in neuronal apoptosis in response to neurotrophic factors and transcription factors and regulators indicative of the activation pathways downstream of the neuronal system. Expression of these genes was reliably analyzed using real-time PCR.

RNA isolation. Total RNA was isolated from white blood cells using NucleoZOL (Macherey-Nagel, Germany) according to the manufacturer's instructions. NucleoZOL is designed for the isolation of total RNA (small and large RNA) in a single or separate fraction from a variety of sample materials, such as cells, tissue, and liquids of human or animal origin. White blood cells were lysed and homogenized in NucleoZOL reagent based on guanidinium thiocyanate and phenol.

cDNA synthesis. The RNA quality was determined using a spectrophotometer and was reverse transcribed. The concentration and quality of the isolated total RNA was determined on a spectrophotometer NanoDrop (Thermo Scientific ${ }^{\mathrm{Tm}}$, USA). For further reverse transcription procedure, using a cDNA conversion RT $^{2}$ First Strand Kit (QIAGEN, Germany, Cat. no. 330401), RNA samples were selected with the following parameters: ratio A260/A280 within the range of $1.8-2.2$.

The RT2 HT First Strand Kit procedure comprises 2 steps: elimination of genomic DNA contamination, and reverse transcription, which enable fast and easy handling of 96 RNA samples simultaneously. After genomic DNA elimination, the RNA sample under- goes reverse transcription with an RT master mix, as well as random hexamers and oligo-dT prime reverse transcription to capture more difficult-to-detect genes.

Pathway-specific real-time PCR array. The cDNA was then used with RTI Profiler PCR Array (QIAGEN, Cat. no. PAHS-031Z) in combination with RTI SYBR ${ }^{\oplus}$ Green qPCR Mastermix (QIAGEN, Cat. no. 330504), following the complete RT2 Profiler PCR Array procedure (www.qiagen.com). Samples were assigned to control and study groups. $\mathrm{C}_{\mathrm{T}}$ values were normalized based on automatic selection from the full panel of reference genes.

The complete RT2 Profiler PCR Array procedure (www.qiagen.com).

Any Ct value $>35$ was considered to be a negative call. The RT2 Profiler PCR Array data analysis software calculates the fold change based on the widely used and agreed upon $\Delta \Delta \mathrm{Ct}$ method. The data analysis web portal calculates fold change/regulation using delta-delta $\mathrm{C}_{\mathrm{T}}$ method, in which delta $\mathrm{C}_{\mathrm{T}}$ is calculated between the gene of interest (GOI) and an average of reference genes (HKG), followed by deltadelta $\mathrm{C}_{\mathrm{T}}$ calculations (delta $\mathrm{C}_{\mathrm{T}}$ (Test Group)-delta $\mathrm{C}_{\mathrm{T}}$ (Control Group)). Fold Change is then calculated using $2^{\wedge}$ (-delta-delta $\mathrm{C}_{\mathrm{T}}$ ) formula. This data analysis report was exported from the QIAGEN web portal at GeneGlobe. The software allows to define the best reference genes for normalization. In further analysis, nerve impulse transmission pathway-focused genes were selected for this work; a list of these genes is given in Table 1.

Table 1

Nerve impulse transmission pathway-focused genes.

\begin{tabular}{llcl}
\hline Unigene & Refseq & Gene Symbol & Description \\
\hline Hs.502182 & NM_001709 & BDNF & Brain-derived neurotrophic factor \\
Hs.458423 & NM_004352 & CBLN1 & Cerebellin 1 precursor \\
\hline Hs.524920 & NM_000614 & CNTF & Ciliary neurotrophic factor \\
\hline Hs.75294 & NM_000756 & CRH & Corticotropin releasing hormone \\
\hline Hs.272191 & NM_001480 & GALR1 & Galanin receptor 1 \\
Hs.666366 & NM_003857 & GALR2 & Galanin receptor 2 \\
Hs.248114 & NM_000514 & GDNF & Glial cell derived neurotrophic factor \\
\hline Hs.158348 & NM_001524 & HCRT & Hypocretin (orexin) neuropeptide precursor \\
Hs.649965 & NM_002397 & MEF2C & Myocyte enhancer factor 2C \\
Hs.733076 & NM_003717 & NPFF & Neuropeptide FF-amide peptide precursor \\
\hline Hs.1832 & NM_000905 & NPY & Neuropeptide Y \\
Hs.590869 & NM_002531 & NTSR1 & Neurotensin receptor 1 (high affinity) \\
Hs.88218 & NM_006228 & PNOC & Prepronociceptin \\
\hline
\end{tabular}


Statistical analysis of PCR array data. The RT2 Profiler PCR Array Data Analysis software does not perform any statistical analysis beyond the calculation of p-values using a Student's t-test (two-tail distribution and equal variances between the two samples) based on the triplicate $2^{\wedge}(-\Delta C T)$ values for each gene in the experimental group compared to the control group. The Microarray Quality Control (MAQC) published results indicating that a ranked list of genes based on fold-change and such a p-value calculation was sufficient to demonstrate reproducible results across multiple microarrays and PCR Arrays including the RT2 Profiler PCR Arrays (Shi et al. 2006).

\section{Results}

Using the Pathway-Focused PCR Array Profiling (Neurotrophins and Receptors $\mathrm{RT}^{2}$ Profiler PCR Array) we have examined the nerve impulse transmission genes expression of patients with primary hypothyroidism as a result of AIT, postoperative hypothyroidism and patients with AIT with rising serum autoantibodies, such as anti-Tg and anti-TPO.

The results from RT2 Profiler analysis of gene expression of the nerve impulse transmission pathway indicated that patients with postoperative hypothyroidism had significantly lower expression of BDNF (by 41.8 times) vs control group (Figure 1A).
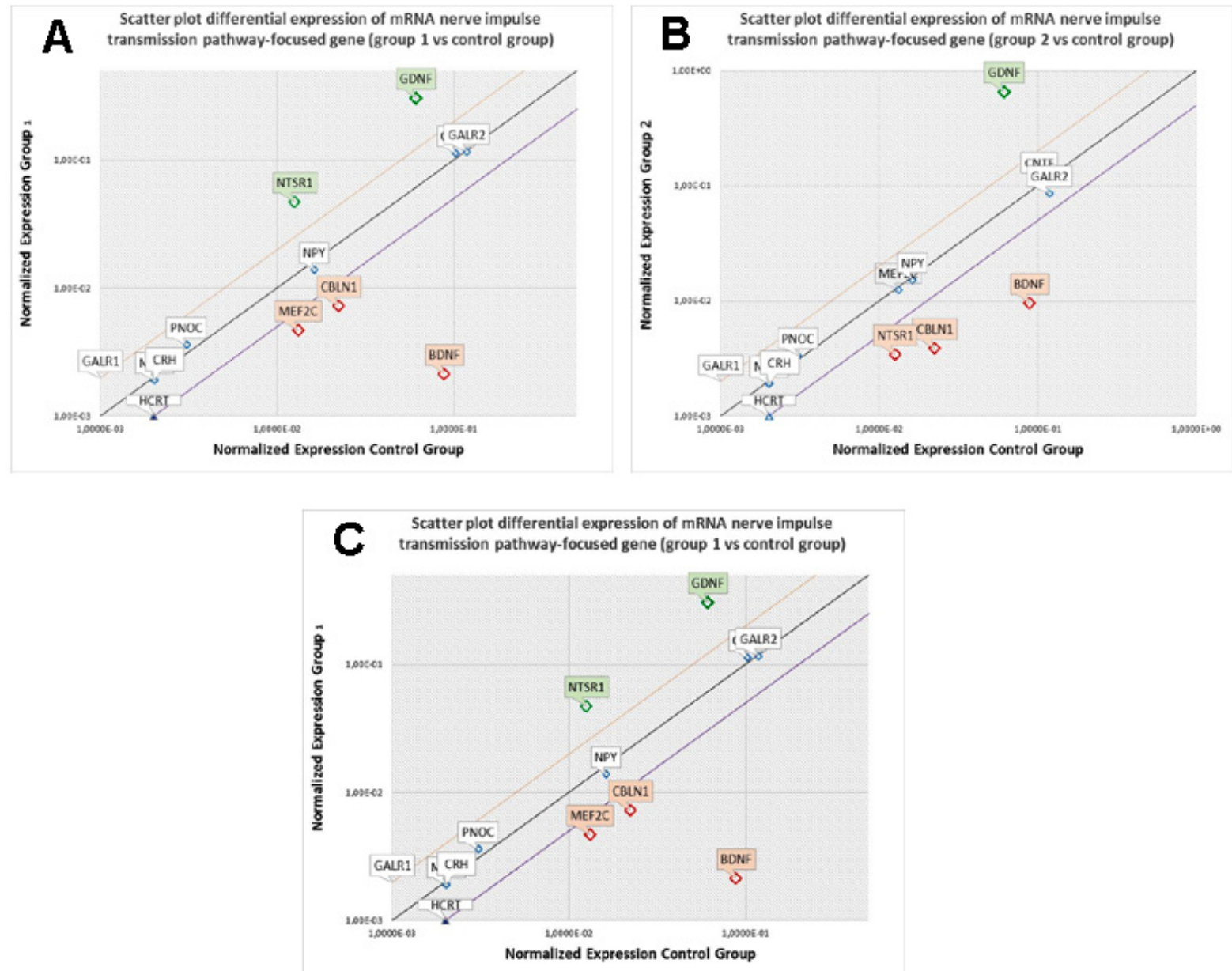

Figure 1. The scatter plot compares the normalized expression of every gene on the array between the two selected groups: control vs. Group 1 (A); control vs. Group 2 (B); control vs. Group 3 (C) by plotting them against one another to quickly visualize large gene expression changes. The central line indicates unchanged genes expression. The sidelines indicate the selected fold regulation threshold. Data points beyond the dotted lines in the upper left and lower right sections meet the selected fold regulation threshold. Green markers $\diamond$ - upregulated genes; blue markers $\diamond$ - unchanged genes; red markers $\diamond$ - downregulated genes. 
Similarly, in patients with hypothyroidism resulting from AIT, BDNF was markedly downregulated (9.3fold) (Figure 1B). In contrast, in Group 3, which included patients with AIT with elevated serum autoantibodies, BDNF expression was up-regulated (3.5fold) (Figure 1C).

As shown in Table 2, GDNF expression significantly increased in Group 1 (5.0-fold) and Group 2 (10.7-fold). Conversely, the expression of GDNF decreased in Group 3 (21.0-fold).

The expression of MEF2C was significantly lower in Group 1, which included patients with postoperative hypothyroidism (2.8-fold) (Figure 1A), while in other groups the expression of MEF2C did not significantly change. As shown in table 2, CBLN1 mRNA was reduced in Group 1 (3.1-fold) and Group 2 (5.8-fold), while in Group 3 CBLN1 was up-regulated (3.4-fold). The expression of NTSR1 was markedly reduced in Group 2 (3.7-fold) and Group 3 (3.6-fold) while in the patients with postoperative hypothyroidism NTSR1 mRNA level significantly elevated (3.7-fold). Notably, in Group 3 PNOC was significantly up-regulated (4.6-fold) (Figure 1C).

The expression of CNTF, CRH, GALR1, GALR2, HCRT, NPFF, NPY genes did not demonstrate differences among the groups.

\section{Discussion}

Thyroid diseases are well known to be able to induce cognitive dysfunction and psychological deficits, including anxiety and depression (Bernal 2017). TH (free triiodothyronine and free thyroxine) which are widely distributed in the central nervous system (CNS), regulate the neuronal growth and formation of synapses between neurons (Loh et al. 2019). Overt hypothyroidism is often associated with clinically significant declines in mood and cognitive function (especially memory), while subclinical hypothyroidism does not typically include symptoms of affective or cognitive dysfunction. However, subtle deficiencies in specific cognitive domains (such as working memory and executive function) were detected in subclinical hypothyroidism (Samuels 2014). Changes in the levels of hormones such as somatostatin and serotonin in the CNS can result in neuropsychiatric manifestations. These changes can potentially affect the hypothalamus-pituitarythyroid (HPT) axis potentially explaining the association between hypothyroidism and depression.

Several studies reported reduced somatostatin levels in cerebrospinal fluid, leading to increased TSH levels in individuals with depression (Ortiga-Carvalho et al. 2016). Patients with clinical and subclinical hypothyroidism demonstrated higher prevalence of depressive symptoms and worse depression scale scores (Zavareh et al. 2016; Siegmann et al. 2018), while hypothyroidism was more prevalent in patients with major depressive disorders (Fugger et al. 2018). A symptom such as anxiety can reach the prevalence of $63-65 \%$ in hypothyroid patients (Andrade-Junio et al. 2010; Siegmann et al. 2018). In a sample of 1503 patients, Medici et al. (2014) found that low TSH levels (0.3-1.0 mIU/L) were associated with more depressive symptoms and more depression diagnoses than high TSH levels (1.6-4.0 mIU/L). In a study by Romero-Gomez et al. (2019), women with hypothyroidism were 3.13 times more likely to suffer from depression and 2.37 times more likely to suffer from anxiety than women without hypothyroidism. At the

Table 2

Differential expression of mRNA nerve impulse transmission pathway-focused genes in different thyroid pathology.

\begin{tabular}{lccc}
\hline \multirow{2}{*}{$\begin{array}{l}\text { Gene } \\
\text { Symbol }\end{array}$} & \multicolumn{3}{c}{ Up-Down Regulation (comparing to the control group) } \\
\cline { 2 - 4 } & $\begin{array}{c}\text { Patients with postoperative } \\
\text { hypothyroidism } \\
\text { (Group 1) }\end{array}$ & $\begin{array}{c}\text { Patients with hypothyroidism } \\
\text { as a result of AIT } \\
\text { (Group 2) }\end{array}$ & $\begin{array}{c}\text { Patients with AIT with rising serum } \\
\text { anti-Tg and anti-TPO autoantibodies } \\
\text { (Group 3) }\end{array}$ \\
\cline { 2 - 4 } & Fold Regulation & Fold Regulation & Fold Regulation \\
\hline BDNF & $-41.8(\mathrm{p}=0.002)$ & $-9.3(\mathrm{p}=0.004)$ & $3.5(\mathrm{p}=0.06)$ \\
CBLN1 & $-3.1(\mathrm{p}=0.004)$ & $-5.8(\mathrm{p}=0.005)$ & $3.4(\mathrm{p}=0.03)$ \\
GDNF & $5.0(\mathrm{p}=0.005)$ & $10.7(\mathrm{p}=0.004)$ & $-21.0(\mathrm{p}=0.0007)$ \\
MEF2C & $-2.8(\mathrm{p}=0.003)$ & $1.1(\mathrm{p}=0.55)$ & $1.7(\mathrm{p}=0.23)$ \\
NTSR1 & $3.7(\mathrm{p}=0.03)$ & $-3.7(\mathrm{p}=0.006)$ & $-3.6(\mathrm{p}=0.005)$ \\
PNOC & $1.2(\mathrm{p}=0.27)$ & $1.1(\mathrm{p}=0.62)$ & $4.6(\mathrm{p}=0.004)$ \\
\hline
\end{tabular}

The p-values are calculated based on a Student's t-test of the replicate $2^{\wedge}(-$ Delta CT) values for each gene in the control group and study groups. Abbreviations: AIT - autoimmune thyroiditis; anti-Tg - anti-thyroglobulin; anti-TPO - anti-thyroid peroxidase. 
same time a meta-analysis performed by Loh et al. (2019) did not show improvement in the symptoms of depression following levothyroxine therapy in individuals with comorbid subclinical hypothyroidism.

Literature on the emotional effects of euthyroid AIT is limited and controversial. An early epidemiological study found no association between thyroid autoantibodies and anxiety or depression, neither crude nor adjusted for T4 and TSH (Cai et al. 2018). In patients with $\mathrm{HT}$ deficiencies in mental well-being were shown to be independent of thyroid function (Kirim et al. 2012; Giynas et al. 2014; Yalcin et al. 2017).

Neuroinflammation is an essential innate response to brain injury. However, uncontrolled neuroinflammation can result in a progression of damage involving brain cells, immune cells, and signaling molecules (Kempuraj et al. 2017). Glial cells, including microglia and astroglia, are the immune cells of the central nervous system and the main cellular regulators of neuroinflammation (Hendriksen et al. 2017). Normally, glial cells exist in the resting state, but under pathological conditions, they become overactivated and release a number of neurotoxic species, such as proinflammatory cytokine interleukin- $1 \beta$ (IL-1 $\beta$ ), tumor necrosis factor- $\alpha$ (TNF- $\alpha$ ), and interleukin-6 (IL-6) (Cai et al. 2018). These events appear to negatively impact the synthesis and reuptake of neurotransmitters involved in mood regulation, especially serotonin (5-HT) (Capuron and Miller 2011). As such, neuroinflammation, characterized by neuroglia activation and the related generation of proinflammatory cytokines, has been acknowledged as a triggering factor for psychiatric conditions (Rosenblat et al. 2014). Cai et al. (2018) showed that AIT induces neuroinflammation and alters associated serotonin signaling in the euthyroid state, which in turn can produce harmful effects of HT on the emotional function.

The most studied of all NTFs is the brain-derived neurotrophic factor (BDNF), which is highly expressed in the brain and has a powerful effect on synapses (Lewin and Carter 2014; Leal et al. 2017). $\mathrm{BDNF}$ in the CNS selectively regulates synapse density (Causing et al. 1997; Gomez-Casati et al. 2010). BDNF plays an important role in brain network development and synchronization of network activities ( $\mathrm{Lu}$ et al. 2014). It is reported that BDNF is directly regulated by thyroid hormones (Wang et al. 2010), for instance BDNF expression in the brain of developing rat pups was significantly reduced after maternal thyroidectomy (Liu et al. 2010; Shafiee et al. 2016). In addition to CNF, BDNF can be detected in peripheral blood cells as well as other tissues (Gass and Hellweg 2010). There is a correlation between peripheral levels of BDNF and concentrations of BDNF in the CNS (Sartorius et al. 2009; Klein et al. 2011). A study using magnetic resonance spectroscopy found correlation between peripheral concentrations of BDNF and neuronal integrity at anterior cingulate cortex (Lang et al. 2007), while BDNF levels in plasma were also linked to brain activity (Skilleter et al. 2015).

Notably, in our study, patients with postoperative hypothyroidism had significantly reduced expression of BDNF. Thus, a sharp decrease in thyroid hormones following thyroid surgery led to a significant suppression of the BDNF expression. In contrast, in patients with hypothyroidism caused by AIT, the decline in the expression of BDNF was not so pronounced. Moreover, in patients with AIT without hypothyroidism, the BDNF expression was increased. One potential caused by with autoimmune thyroiditis, compensatory mechanisms get involved maintaining BMP expression in contrast to postoperative. Therefore, we can suggest that hypothyroidism affects the expression of the BDNF. Further research in this area will help bridge the gap in understanding its connection with neurophysiological mechanisms and cognitive functions, as well as pathophysiological conditions in disorders of the nervous system comorbid with thyroid pathology.

GDNF also promotes formation of synapses in the hippocampus, so it is likely that BDNF and GDNF interact in the formation of synapses involved in learning (Ledda et al. 2007). A decrease in the levels of GDNF, ARTN, and NT-3 mRNA expression in peripheral blood cells was found in patients with major depressive disorder (Otsuki et al. 2008). In our study, GDNF was significantly down-regulated in the group of patients with rising serum autoantibodies, such as anti-Tg and anti-TPO, while in other groups its expression has increased. NTFs also play important roles outside of the nervous system. They interact with the immune system, and their effects are determined by the site of production and local environment (Linker et al. 2009). Thus, we can propose that elevated anti-Tg and anti-TPO levels inhibit the expression of GDNF.

MEF2 is a family of proteins that promote neuronal survival and regulate dendrite morphogenesis, differentiation of post-synaptic structures and excitatory synapse number (Flavell et al. 2006; Shalizi et al. 2006). MEF2C facilitates context-dependent fear conditioning that is a salient aspect of hippocampusdependent learning and memory (Barbosa et al. 2008). Decreased MEF2C mRNA expression levels in 
leukocytes were proposed as a diagnostic marker for Alzheimer's disease (AD) (Sao et al. 2018). We found that patients with postoperative hypothyroidism had a significantly lower expression of MEF2C compared to the control group. Thus, thyroid hormones deficiency rather than an increased titer of antibodies such as anti-Tg and anti-TPO inhibits expression of MEF2C.

CBLN1 is a protein involved in synapse formation in the CNS (Hirai et al. 2005). A significant decrease in the Cbln1-related peptide concentration has been reported for certain neurological disorders (Mizuno et al. 1995), indicating its important role and potential diagnostic significance in detecting synaptic integrity in various physiological and pathological conditions of the adult brain. We found that hypothyroidism was associated with suppressed CBLNlexpression, while the high level of serum autoantibodies, such as an anti-Tg and anti-TPO antobodies were associated with increased the expression of CBLN1.

Neurotensin (NTS) regulates a wide range of physiological processes and is linked to the pathogenesis of diverse conditions, including obesity, hypotension, hypothermia, analgesia, drug addiction, Parkinson's disease, cancer-cell growth, and schizophrenia (Mustain et al. 2011; Boules et al. 2013). Most of the biological effects of neurotensin are mediated through NTSR1 (Kitabgi 2002; Wu et al. 2013). In our study, the NTSR1 was downregulated in Groups 2 and 3. Meanwhile, in the group of patients with postoperative hypothyroidism NTSR1 was up-regulated (Figure 1A). These results suggest that the high level of serum autoantibodies, such as anti-Tg and antiTPO can suppress the expression of NTSR1.

We did not detect changes in the transcriptional activity of a number of genes. CNTF, CRH, GALR1, GALR2, HCRT, NPFF, and NPY did not change their expression in all groups of patients. At the same time, we believe that induction or repression in the blood cells of individual regulatory genes involved in the transmission of nerve impulses is a potential prognostic indicator of the risk of neurological complications in patients with thyroid pathologies. Even though the expression of synaptogenesis regulatory genes is not critical for the function of blood cells, a recent study (Tanabe et al. 2018) described transdifferentiation of mature peripheral $\mathrm{T}$ cells into induced neuronal (iN) cells. The authors showed that mononuclear cells in human adult peripheral blood and defined purified T lymphocytes could be converted into fully functional iN cells. These iN cells showed stereotypical neuronal morphologies, expressed multiple pan-neuronal markers and were able to form functional synapses. Subsequent RNA sequencing (RNA-seq) showed that the up-regulated genes were enriched for Gene Ontology terms such as nervous system development and synaptic transmission, while the down-regulated genes were enriched for cellular defense responses (Tanabe et al. 2018).

Many of these questions are still undergo active investigation. Further study of the role of NTFs in synaptogenesis makes it possible to discover new signaling pathways and present new insights into how neuronal circuits are wired. These questions can be approached through advanced genomic and proteomic analysis, as well as the use of high-tech imaging technologies. At the same time, the effect of $\mathrm{TH}$ on the brain and their insufficiency in development of neurological complications are already well recognized. Therefore, in the cases of thyroid gland disorders it is important to detect early damage to the nervous system in order to prevent and treat further complications.

In conclusion, the results of this study demonstrate that autoimmune thyroiditis and hypothyroidism can affect the expression of mRNA nerve impulse transmission genes in gene specific manner and that these changes in gene expressions can be playing a role in the development of neurological complications associated with thyroid pathology. Detection of the transcriptional activity of nerve impulse transmission genes in peripheral white blood cells can be used as an important minimally invasive prognostic marker of the risk for developing neurological complications comorbid with thyroid pathology.

\section{References}

Andrade-Junio NE, Pires ML, Thuler LC. Depression and anxiety symptoms in hypothyroid women. Rev Bras Ginecol Obstet 32, 321-326, 2010.

Barbosa AC, Kim MS, Ertunc M, Adachi M, Nelson ED, McAnally J, Richardson JA, Kavalali ET, Monteggia LM, Bassel-Duby R, Olson EN. MEF2C, a transcription factor that facilitates learning and memory by negative regulation of synapse numbers and function. Proc Natl Acad Sci USA 105, 9391-9396, 2008.

Bathla M, Singh M, Relan P. Prevalence of anxiety and depressive symptoms among patients with hypothyroidism. Indian J Endocrinol Metab 20, 468-474, 2016. 
Bernal J. Thyroid hormone regulated genes in cerebral cortex development. J Endocrinol 232, R83-R97, 2017.

Bonner JF, Connors TM, Silverman WF, Kowalski DP, Lemay MA, Fischer I. Grafted neural progenitors integrate and restore synaptic connectivity across the injured spinal cord. J Neurosci 31, 4675-4686, 2011.

Boules M, Li Z, Smith K, Fredrickson P, Richelson E. Diverse roles of neurotensin agonists in the central nervous system. Front Endocrinol (Lausanne) 4, 36, 2013.

Cai YJ, Wang F, Chen ZX, Li L, Fan H, Wu ZB, Ge JF, Hu W, Wang QN, Zhu DF. Hashimoto's thyroiditis induces neuroinflammation and emotional alterations in euthyroid mice. J Neuroinflammation 15, 299, 2018.

Capuron L, Miller AH. Immune system to brain signaling: neuropsychopharmacological implications. Pharmacol Ther 130, 226-238, 2011.

Causing CG, Gloster A, Aloyz R, Bamji SX, Chang E, Fawcett J, et al. Synaptic innervation density is regulated by neuron-derived BDNF. Neuron 18, 257-267, 1997.

Chen A, Muzzio IA, Malleret G, Bartsch D, Verbitsky M, Pavlidis P, Yonan AL, Vronskaya S, Grody MB, Cepeda I, Gilliam TC, Kandel ER. Inducible enhancement of memory storage and synaptic plasticity in transgenic mice expressing an inhibitor of atf4 (creb-2) and c/ebp proteins. Neuron 39, 655-669, 2003.

Davis JD, Tremont G. Neuropsychiatric aspects of hypothyroidism and treatment reversibility. Minerva Endocrinol 32, 49-65, 2007.

Flavell SW, Cowan CW, Kim TK, Greer PL, Lin Y, Paradis S, Griffith EC, Hu LS, Chen C, Greenberg ME. Activity-dependent regulation of MEF2 transcription factors suppresses excitatory synapse number. Science 311, 1008-1012, 2006.

Fox MA, Umemori H. Seeking long-term relationship: axon and target communicate to organize synaptic differentiation. J Neurochem 97, 1215-1231, 2006.

Fugger G, Dold M, Bartova L, Kautzky A, Souery D, Mendlewicz J, Serretti A, Zohar J, Montgomery S, Frey R, Kasper S. Comorbid thyroid disease in patients with major depressive disorder - results from the European Group for the Study of Resistant Depression (GSRD). Eur Neuropsychopharmacol 28, 752-760, 2018.

Garber JR Cobin R.H, Gharib H, Hennessey JV, Klein I, Mechanick JI, Pessah-Pollack R, Singer PA, Woeber KA. Clinical practice guidelines for hypothyroidism in adults: cosponsored by the American Association of Clinical Endocrinologists and the American Thyroid Association. Endocr Pract 18, 988-1028, 2012.

Gass P, Hellweg R. Peripheral brain-derived neurotrophic factor (BDNF) as a biomarker for affective disorders? Int J Neuropsychopharmacol 13, 1-4, 2010.

Giynas AM, Uguz F, Askin R, Gonen MS. The prevalence of depression and anxiety disorders in patients with euthyroid Hashimoto's thyroiditis: a comparative study. Gen Hosp Psychiatry 36, 95-98, 2014.

Gomez-Casati ME, Murtie JC, Rio C, Stankovic K, Liberman MC, Corfas G. Nonneuronal cells regulate synapse formation in the vestibular sensory epithelium via erbB-dependent BDNF expression. Proc Natl Acad Sci USA 107, 17005-17010, 2010.

Hendriksen E, van Bergeijk D, Oosting RS, Redegeld FA. Mast cells inneuroinflammation and brain disorders. Neurosci Biobehav Rev 79, 119-133, 2017.

Hirai H, Pang Z, Bao D, Miyazaki T, Li L, Miura E, Parris J, Rong Y, Watanabe M, Yuzaki M, Morgan JI. Cbln1 is essential for synaptic integrity and plasticity in the cerebellum. Nat Neurosci 8, 1534-1541, 2005.

Juceviciute N, Zilaitiene B, Aniuliene R, Vanagiene V. The Link between Thyroid Autoimmunity, Depression and Bipolar Disorder. Open Med (Wars) 14, 52-58, 2019.

Kempuraj D, Thangavel R, Selvakumar GP, Zaheer S, Ahmed ME, Raikwar SP, Zahoor H, Saeed D, Natteru PA, Iyer $S$, Zaheer A. Brain and peripheral atypical inflammatory mediators potentiate Neuroinflammation and neurodegeneration. Front Cell Neurosci 11, 216, 2017.

Kirim S, Keskek SO, Koksal F, Haydardedeoglu FE, Bozkirli E, Toledano Y. Depression in patients with euthyroid chronic autoimmune thyroiditis. Endocr J 59, 705-708, 2012.

Kitabgi P. Targeting neurotensin receptors with agonists and antagonists for therapeutic purposes. Curr Opin Drug Discov Devel 5, 764-776, 2002.

Klein AB, Williamson R, Santini MA, Clemmensen C, Ettrup A, Rios M, Knudsen GM, Aznar S. Blood BDNF concentrations reflect brain-tissue BDNF levels across species. Int J Neuropsychopharmacol 14, 347-353, 2011.

Kotwal SK, Kotwal S, Gupta R, Singh JB, Mahajan A. Cerebellar ataxia as presenting feature of hypothyroidism. Arch Endocrinol Metab 60, 183-185, 2016.

Koval HD, Chopyak VV, Kamyshnyi OM, Kurpisz MK. Transcription regulatory factor expression in T-helper cell differentiation pathway in eutopic endometrial tissue samples of women with endometriosis associated with infertility. Cent Eur J Immunol 43, 90-96, 2018. 
Lang UE, Hellweg R, Seifert F, Schubert F, Gallinat J. Correlation between serum brain-derived neurotrophic factor level and an in vivo marker of cortical integrity. Biol Psychiatry 62, 530-535, 2007.

Leal G, Bramham CR, Duarte CB. BDNF and hippocampal synaptic plasticity. Vitam Horm 104, 153-195, 2017.

Ledda F, Paratcha G, Sandoval-Guzman T, Ibanez CF. GDNF and GFRa1 promote formation of neuronal synapses by ligand-induced cell adhesion. Nat Neurosci 10, 293-300, 2007.

Lewin GR, Carter BD. Neurotrophic Factors. Preface. Handb Exp Pharmacol 220, v-vi, 2014.

Lu B, Nagappan G, Lu Y. BDNF and synaptic plasticity, cognitive function, and dysfunction. Handb Exp Pharmacol 220, 223-250, 2014.

Linker R, Gold R, Luhder F. Function of neurotrophic factors beyond the nervous system: inflammation and autoimmune demyelination. Crit Rev Immunol 29, 43-68, 2009.

Liu D, Teng W, Shan Z, Yu X, Gao Y, Wang S, Fan C, Wang H, Zhang H. The Effect of maternal subclinical hypothyroidism during pregnancy on brain development in rat offspring. Thyroid 20, 909-915, 2010.

Loh HH, Lim LL, Yee A, Loh HS. Association between subclinical hypothyroidism and depression: an updated systematic review and meta-analysis. BMC Psychiatry 19, 12, 2019.

Medici M, Direk N, Visser WE, Korevaar TI, Hofman A, Visser TJ. Thyroid function within the normal range and the risk of depression: A population-based cohort study. J Clin Endocrinol Metab 99, 1213-1219, 2014.

Miyamoto A, Wake H, Ishikawa AW, Eto K, Shibata K, Murakoshi H, Koizumi S, Moorhouse A, Yoshimura Y, Nabekura J. Microglia contact induces synapse formation in developing somatosensory cortex. Nat Commun 7, 12540, 2016.

Mizuno Y, Takahashi K, Totsune K, Ohneda M, Konno H, Murakami O, Satoh F, Sone M, Takase S, Itoyama Y, et al. Decrease in cerebellin and corticotropin-releasing hormone in the cerebellum of olivopontocerebellar atrophy and Shy-Drager syndrome. Brain Res 686, 115-118, 1995.

Mustain WC, Rychahou PG, Evers BM. The role of neurotensin in physiologic and pathologic processes. Curr Opin Endocrinol Diabetes Obes 18, 75-82, 2011.

Ortiga-Carvalho TM, Chiamolera MI, Pazos-Moura CC, Wondisford FE. Hypothalamus-pituitary-thyroid Axis. Compr Physiol 6, 1387-1428, 2016.

Otsuki K, Uchida S, Watanuki T, Wakabayashi Y, Fujimoto M, Matsubara T, Funato H, Watanabe Y. Altered expression of neurotrophic factors in patients with major depression. J Psychiatr Res 42, 1145-1153, 2008.

Parkhurst CN, Yang G, Ninan I, Savas JN, Yates JR, Lafaille JJ, Hempstead BL, Littman DR, Gan WB. Microglia promote learning-dependent synapse formation through brain-derived neurotrophic factor. Cell 155, 15961609, 2013.

Petzoldt AG, Sigrist SJ. Synaptogenesis. Current Biology 24, R1076-1080, 2014.

Poyhonen S, Er S, Domanskyi A, Airavaara M. Effects of neurotrophic factors in glial cells in the central nervous system: expression and properties in neurodegeneration and injury. Front Physiol 10, 486, 2019.

Putilin DA, Kamyshnyi AM. Changes of glut1, mtor and ampkla gene expression in pancreatic lymph node lymphocytes of rats with experimental diabetes mellitus. Medical Immunology (Russia) 18, 339-346, 2016.

Romero-Gomez B, Guerrero-Alonso P, Carmona-Torres JM, Notario-Pacheco B, Cobo-Cuenca AI. Mood disorders in levothyroxine-treated hypothyroid women. Int J Environ Res Public Health 16, 4776, 2019.

Rosenblat JD, Cha DS, Mansur RB, McIntyre RS. Inflamed moods: a review of the interactions between inflammation and mood disorders. Prog Neuro-Psychopharmacol Biol Psychiatry 53, 23-34, 2014.

Samuels MH. Psychiatric and cognitive manifestations of hypothyroidism. Curr Opin Endocrinol Diabetes Obes 21, 377-383, 2014.

Sao T, Yoshino Y, Yamazaki K, Ozaki Y, Mori Y, Ochi S, Yoshida T, Mori T, Iga JI, Ueno SI. MEF2C mRNA expression and cognitive function in Japanese patients with Alzheimer's disease. Psychiatry Clin Neurosci 72, 160-167, 2018.

Sartorius A, Hellweg R, Litzke J, Vogt M, Dormann C, Vollmayr B, Danker-Hopfe H, Gass P. Correlations and discrepancies between serum and brain tissue levels of neurotrophins after electroconvulsive treatment in rats. Pharmacopsychiatry 42, 270-276, 2009.

Shafiee SM, Vafaei A, Rashidy-Pour A. Effects of maternal hypothyroidism during pregnancy on learning, memory and hippocampal BDNF in rat pups: Beneficial effects of exercise. Neuroscience 329, 151-61, 2016.

Shalizi A, Gaudilliere B, Yuan Z, Stegmuller J, Shirogane T, Ge Q, Tan Y, Schulman B, Harper JW, Bonni A. A calcium-regulated MEF2 sumoylation switch controls postsynaptic differentiation. Science 311, 1012-1017, 2006.

Shcherba V, Vydoinyk O, Posolenyk L, Korda M. The influence of thyroid hormones on mitochondrial mechanisms of blood neutrophils' apoptosis in case of experimental periodontitis. Arch Balk Med Union 54, 64-71, 2019. 
Shi L, Reid LH, Jones WD, Shippy R, Warrington JA, Baker SC, et al. The MicroArray Quality Control (MAQC) project shows inter- and intraplatform reproducibility of gene expression measurements. Nat Biotechnol 24, 1151-1161, 2006.

Siegmann EM, Muller HHO, Luecke C, Philipsen A, Kornhuber J, Gromer TW. Association of depression and anxiety disorders with autoimmune thyroiditis: A systematic review and meta-analysis. JAMA Psychiatry 75, 577-584, 2018.

Skilleter AJ, Weickert CS, Vercammen A, Lenroot R, Weickert TW. Peripheral BDNF: a candidate biomarker of healthy neural activity during learning is disrupted in schizophrenia. Psychol Med 45, 841-854, 2015.

Tanabe K, Ang CE, Chanda S, Olmos VH, Haag D, Levinson DF, Sudhof TC, Wernig M. Transdifferentiation of human adult peripheral blood T cells into neurons. Proc Natl Acad Sci U S A. 115, 6470-6475, 2018.

Topol IA, Kamyshny AM, Abramov AV, Kolesnik YM. Expression of XBP1 in lymphocytes of the small intestine in rats under chronic social stress and modulation of intestinal microflora composition. Fiziolohichnyi zhurnal 60, 38-44, 2014.

Tronko M, Mabuchi K, Bogdanova T, Hatch M, Likhtarev I, Bouville A, Oliynik V, McConnell R, Shpak V, Zablotska L, Tereshchenko V, Brenner A, Zamotayeva G. Thyroid cancer in Ukraine after the Chernobyl accident (in the framework of the Ukraine-US Thyroid Project). J Radiol Prot 32, 65-69, 2012.

Wang Y, Hou Y, Dong J, Xu H, Gong J, Chen J. Developmental iodine deficiency and hypothyroidism reduce phosphorylation of calcium/calmodulin-dependent kinase II in the rat entorhinal cortex. Biol Trace Elem Res 137, 353-363, 2010.

Wu Z, Martinez-Fong D, Tredaniel J, Forgez P. Neurotensin and its high affinity receptor 1 as a potential pharmacological target in cancer therapy. Front Endocrinol 3, 184, 2013.

Yalcin MM, Altinova AE, Cavnar B, Bolayir B, Akturk M, Arslan E, Ozkan C, Cakir N, Balos Toruner F. Is thyroid autoimmunity itself associated with psychological well-being in euthyroid Hashimoto's thyroiditis? Endocr J 64, 425-429, 2017.

Zavareh AT, Jomhoury R, Bejestani HS, Arshad M, Daneshmand M, Ziaei H, Babadi N, Amiri M. Depression and hypothyroidism in a population-based study of Iranian women. Rom J Intern Med 54, 217-221, 2016. 